\title{
CORONAVIRUS Y LIBERTAD DE EMPRESA
}

\author{
Antonio Cidoncha Martín \\ Profesor contratado doctor \\ Universidad Autónoma de Madrid
}

Cómo citar este artículo / Citation: Cidoncha Martín, Antonio. (2020). Coronavirus y libertad de empresa. Biglino Campos, P.; Durán Alba, F. Los Efectos Horizontales de la COVID sobre el sistema constitucional, Colección Obras colectivas, Fundación Manuel Giménez Abad,

Zaragoza.

DOI: https://doi.org/10.47919/FMGA.OC20.0015

SUMARIO: I. INTRODUCCIÓN - II. SOBRE LA LIBERTAD DE EMPRESA COMO DERECHO FUNDAMENTAL - III. LA LIBERTAD DE EMPRESA Y LOS ESTADOS DE ANOMALÍA CONSTITUCIONAL - 1. Estados de anomalía constitucional, CE y libertad de empresa - 2. Estado de alarma, LOAES y libertad de empresa. IV. LA LIBERTAD DE EMPRESA DURANTE LA VIGENCIA DEL ESTADO DE ALARMA DECLARADO EL 14 DE MARZO DE 2020 - 1. La declaración del estado de alarma y la libertad de empresa a) Consideraciones generales - b) En particular, el artículo 10 del decreto de declaración del estado de alarma - 2. Los decretos-leyes aprobados durante la vigencia del estado de alarma y la libertad de empresa - a) Consideraciones generales - b) Consideraciones particulares desde la libertad de empresa V. Libertad de empresa y nueva normalidad - VI. Epílogo - VII. BIBLIOGRAFÍA

\section{INTRODUCCIÓN}

Cualquiera que se haya aproximado a la crisis del coronavirus sabe que el 30 de enero de 2020 la OMS declaró la situación de emergencia de salud pública y que, ante la galopante propagación del virus, declaró finalmente la situación de pandemia el 11 de marzo de 2020. También sabe que, entre estas dos 
fechas, la respuesta a la epidemia que devino pandemia la dieron las autoridades autonómicas y los ayuntamientos ${ }^{1}$.

La respuesta jurídica del Estado se hizo esperar, pero llegó de forma abrupta, con la declaración del estado de alarma en todo el territorio nacional, el 14 de marzo de $2020^{2}$. En palabras del propio Gobierno, la articulación jurídica de su respuesta a la pandemia se estructuró en torno a dos instrumentos constitucionales: por un lado, la declaración del estado de alarma (y sus prórrogas) y las medidas adoptadas en su virtud, tanto "limitativas" de la libertad de circulación como de "contención" en diversos ámbitos; por otro lado, la adopción de sucesivos decretos-leyes, fundamentalmente dirigidos a paliar las consecuencias negativas en el ámbito socioeconómico de la pandemia y de las medidas de contención adoptadas para contenerlas ${ }^{3}$.

Analizaré el impacto de esas respuestas jurídicas sobre la libertad de empresa (apartado IV). Este análisis, que es jurídico-constitucional, exige previamente saber cómo entiende el Tribunal Constitucional la libertad de empresa (apartado II) y qué es lo que puede hacer (y lo que no) con ella nuestro Derecho Constitucional y legal de los estados de anomalía constitucional (apartado III). Como el fin del estado de alarma no ha supuesto el fin de la crisis sanitaria, se impone hacer algún apunte sobre el impacto jurídico de la "nueva normalidad" en la libertad de empresa (apartado V).

\section{SOBRE LA LIBERTAD DE EMPRESA COMO DERECHO FUNDAMENTAL}

En el artículo 38 de la Constitución (CE en adelante) se dispone lo siguiente: "Se reconoce la libertad de empresa en el marco de la economía de mercado". La libertad que se reconoce tiene un titular, el empresario privado ${ }^{4}$, un objeto, la actividad empresarial ${ }^{5}$ y un contenido. Sobre el contenido se ha volcado la

1 Una panorámica general de las medidas adoptadas, en Villar Crespo, 2020: 3.

2 Con anterioridad, el Gobierno aprobó dos decretos-leyes (el 6/2020, de 10 de marzo y el $7 / 2020$, de 12 de marzo) y dictó dos órdenes ministeriales que restringían el tráfico aéreo y marítimo con Italia (las PCM/205/2020 y 216/2020).

3 Exposición de Motivos del Real Decreto-ley 21/2020, de 9 de junio.

4 Titulares del artículo 38 son las "empresas privadas" (STC 49/1988, FJ 12). Sobre esta cuestión, Cidoncha, 2006: 222.

5 Lo que protege el artículo 38 CE no es toda actividad económica, sino la actividad económica profesional, organizada, desarrollada en nombre propio y dirigida a producir bienes y servicios para el mercado. Sobre esta cuestión, Cidoncha, 2006: 254. 
jurisprudencia del Tribunal Constitucional (TC en adelante). Para este, la libertad de empresa consiste en el derecho a iniciar y sostener en libertad la actividad empresarial (STC 83/1984, FJ 5). La capacidad de decisión que otorga a su titular se proyecta: en el inicio, como libertad de creación de empresas $^{6}$; en el ejercicio, como libertad de actuación en el mercado (proyección ad extra) ${ }^{7}$ y como libertad de organización (proyección ad intra) ${ }^{8}$; y, en el final, como libertad de cesar en la actividad empresarial ${ }^{9}$.

EL TC nunca ha negado que la libertad de empresa sea un derecho fundamental y que, como tal, goce de la doble garantía propia de los derechos fundamentales: reserva de ley e indisponibilidad para la ley de su contenido esencial $^{10}$. Sin embargo, no han faltado ocasiones en que ha debilitado su condición de derecho subjetivo, bien porque la ha calificado abiertamente como garantía institucional ${ }^{11}$, bien porque, más suavemente, ha declarado que en ella "predomina, como es patente, el carácter de garantía institucional" 12. El predominio de lo institucional, identificado con la defensa del interés general económico (las exigencias de la economía general ex art. $38 \mathrm{CE}$ ), ha servido de base al TC para afirmar que la libertad de empresa debe ejercerse "con plena sujeción a la normativa sobre ordenación del mercado y de la actividad económica general" [STC 225/1993, FJ 3 B) -la cursiva es mía].

Sin embargo, en jurisprudencia más reciente, ha aclarado que las "reglas estatales o autonómicas que ordenan la economía de mercado deben, por tanto, ser conformes con la doble garantía constitucionalmente establecida del derecho fundamental a la libertad de empresa: la de la reserva de ley y la que resulta de la atribución a cada derecho o libertad de un contenido esencial, un núcleo del que ni siquiera el legislador puede disponer" (STC 53/2014, FJ 7) ${ }^{13}$. La libertad de empresa es, por tanto, un derecho fundamental, con una relevante dimensión institucional, cierto, pero derecho fundamental con un

6 La libertad de empresa entraña el reconocimiento a los particulares de una libertad de decisión para crear empresas y, por tanto, para actuar en el mercado (STC 225/1993, FJ 3 B).

7 Como libertad para establecer los propios objetivos de la empresa y dirigir y planificar su actividad en atención a sus recursos y a las condiciones del propio mercado (ibidem). En la STC 112/2006 precisa: esa libertad de actuación en el mercado comprende la libertad de contratación e inversión (FJ 4).

8 De nuevo STC 112/2006, FJ 4.

9 En concreto, la libertad de empresa comprende la libre transmisión de la empresa (STC 109/2003, FJ 8).

10 STC 37/1981, FJ 2.

11 SSTC 11/1983, FJ 10, 87/1985, FJ 8 y 136/1991, FJ 1.

12 SSTC 83/1984, FJ 3 y 225/1993, FJ 3 B.

13 En idéntico sentido, STC 89/2017, FJ 14. 
contenido esencial del que el legislador no puede disponer. La pregunta es: ¿cuál es el contenido esencial de la libertad de empresa?

EI TC no ha escrutado nunca las medidas legales limitativas de la libertad de empresa con los criterios de la sentencia 11/1981, esto es, desde la llamada "teoría absoluta" de los derechos fundamentales. Lo ha hecho tradicionalmente desde la "teoría relativa", apelando al principio de proporcionalidad, ma non troppo. Ha juzgado el respeto al contenido esencial de las medidas limitativas (o directamente prohibitivas) de la libertad de empresa desde, aparentemente, un principio de proporcionalidad mutilado, esto es, circunscrito a los dos primeros test del mismo (idoneidad y necesidad), con exclusión del tercero (proporcionalidad en sentido estricto). Digo aparentemente, porque, en realidad, el TC, bajo el manto de la proporcionalidad mutilada, ha aplicado en realidad un mero control de razonabilidad de la medida limitativa 0 , en otros términos, un mero test de idoneidad ${ }^{14}$.

Todo disimulo desaparece en la sentencia 53/2014. En ella el TC rechaza abiertamente emplear el test de necesidad: lo único que le compete es analizar si la medida limitativa en cuestión es "adecuada para la consecución de un fin legítimo, sin que le corresponda a este Tribunal ir más allá, pues ello supondría fiscalizar la oportunidad de una concreta elección del legislador, de una legítima opción política" (STC 53/2014, FJ 7). La deferencia al legislador es, por tanto, amplísima. Es más, el TC llega al punto de permitir a legislador la invocación de fines no enunciados en la $\mathrm{CE}^{15}$ : fin apto para limitar la libertad de empresa es cualquier fin no prohibido expresamente por la CE, siempre que responda a un interés general legítimo. Lo único proscrito al legislador, en resumidas cuentas, es la arbitrariedad.

Un cambio de enfoque se aprecia en la STC 35/2016 (FJ 4) ${ }^{16}$ y parece consolidarse en las SSTC 89/2017 (FJ 14) y 111/2017 [FJ 4 a)]. Con arreglo a la nueva jurisprudencia, tenemos un doble canon de control, según que la medida limitativa afecte al "acceso" al mercado, esto es, a la libertad de inicio de la actividad empresarial, o solo al "ejercicio" de la actividad empresarial, sin

14 Esto es muy visible en las STC 225/1993, pero también en las SSTC 109/2003 y 112/2006, sentencias posteriores a la 66/1995, en la que el TC introdujo el principio de proporcionalidad al modo alemán, con el triple test de idoneidad, necesidad y proporcionalidad en sentido estricto. Si no estoy equivocado, la única sentencia en la que el TC razona empleando el doble test de idoneidad y necesidad es la 66/1991, en la que resuelve sobre la constitucionalidad de una medida prohibitiva contenida en una norma reglamentaria.

15 Vid. STC 83/1984, FJ 3.

16 Se atisba en la STC 53/2014, FJ 7, a la que hace mención la STC 35/2016. 
afectar al acceso a la misma. En el primer caso (acceso al mercado), el canon de control es el de proporcionalidad mutilada: la medida limitativa del acceso al mercado será constitucional si supera los test de idoneidad y necesidad. En el segundo caso (ejercicio de la actividad empresarial ya iniciada), el único canon de control, según la STC 35/2016, es el de idoneidad, como de costumbre: la medida limitativa del ejercicio de la actividad empresarial será constitucional si es "adecuada" o idónea para la consecución de un fin legítimo (fin no necesariamente constitucional).

Como se ve, para el TC la libertad de empresa no es un derecho fundamental como los demás: tiene dos cánones de control del respeto a su contenido esencial. Además, en ninguno de esos cánones se aplica el principio de proporcionalidad en su totalidad (no sé por qué): en lo que hace a la libertad de "acceso" al mercado, se omite el tercer test (el de proporcionalidad en sentido estricto) y, en lo que respecta a la libertad de "ejercicio", se reduce al primero de los test (el de idoneidad).

Sin embargo, en la sentencia 89/2017 [FJ 14 b)], el TC añade sorprendentemente un nuevo test a la limitación de la libertad de ejercicio (más propio de un entendimiento "absoluto" de la regla del artículo $53.1 \mathrm{CE}$ ): la medida limitativa es constitucional si, además de ser adecuada para alcanzar un objetivo legítimo, no conlleva, debido a su intensidad, una privación del referido derecho; o, para ser más precisos, no supone un impedimento práctico para su ejercicio. En el mismo sentido se pronuncia la STC 111/2017 [FJ 4 a)]. ¿Va en serio el TC? Retenga este párrafo el lector, de cara a las páginas que se avecinan.

\section{LA LIBERTAD DE EMPRESA Y LOS ESTADOS DE ANOMALÍA CONSTITUCIONAL}

1. Estados de anomalía constitucional, CE y libertad de empresa

La CE no ha incluido la libertad de empresa entre los derechos fundamentales que pueden ser suspendidos si se declaran los estados de excepción y de sitio (art. 55). Fuera o no previsor el legislador constituyente, este es un dato de partida que no se puede soslayar. En ninguno de los estados de anomalía constitucional (alarma, excepción y sitio) se puede suspender la libertad de empresa. 
Que sea "suspender" un derecho fundamental es algo sobre lo que debate intensamente la doctrina, a cuenta sobre todo del famoso artículo 7 del decreto de declaración de estado de alarma (en el que se "limita" la libertad de circulación). Estamos a la espera de doctrina del TC al respecto. No me corresponde entrar en ese debate. Lo que importa para el objeto de nuestro trabajo: en cualquiera de los estados de anomalía constitucional se puede limitar temporalmente la libertad de empresa, pero no lesionar su contenido esencial. La regla del artículo 53.1 CE rige en su plenitud, cualquiera que sea el estado que se declare.

El contenido esencial de los derechos fundamentales es resistente a la ley, pero no a la CE misma, que puede introducir excepciones. En tiempos de excepción y sitio, se puede excepcionar la regla del artículo 53.1 CE, suspendiendo ciertos derechos fundamentales, pero entre ellos no está la libertad de empresa. Sin embargo, tanto en tiempos de normalidad como de anormalidad, la regla que obliga a la ley a respetar la libertad de empresa (art. 53.1 CE, en conexión con el art. 38) es excepcionable si se ponen en práctica las cláusulas habilitadoras del segundo inciso del artículo $128.2 \mathrm{CE}$. Esta norma constitucional excluye del ámbito de aplicación de la libertad de empresa los recursos o servicios esenciales reservados al sector público o las empresas intervenidas mediante ley ${ }^{17}$.

\section{Estado de alarma, LOAES y libertad de empresa}

La Ley Orgánica 4/1981, de 1 de junio, de los estados de alarma, excepción y sitio (LOAES en adelante), a la que reserva la CE la regulación de los estados de anomalía constitucional (art. 116.1), no puede regular medidas que supongan suspensión de la libertad de empresa, pero sí limitaciones respetuosas con su contenido esencial o amparadas en el artículo 128.2 CE. Pues bien, en su articulado nos encontramos con medidas que tienen un evidente impacto sobre la libertad de empresa.

En lo que aquí nos interesa, el estado de alarma, la LOAES habilita al decreto de declaración de estado de alarma para dictar determinadas medidas concretas que afectan directamente ${ }^{18}$ al ejercicio de la libertad de empresa:

17 Sobre esto, Cidoncha, 2006: 332.

18 Una requisa temporal de bienes [art. 11.b)] también afecta a la libertad de empresa, pero más directamente al derecho de propiedad. También afecta más directamente al derecho de 
1. La intervención transitoria de industrias, fábricas, talleres, explotaciones o locales de cualquier naturaleza [art. 11.c)] o, más genéricamente, la intervención de empresas [art. 12.2]. La base constitucional de esta medida es el artículo 128.2 CE, excepción a la regla del artículo 53.1 CE, en conexión con el artículo $38 \mathrm{CE}$.

2. La limitación o racionamiento del uso de servicios o el consumo de artículos de primera necesidad [art.11.d)]. Una medida tal afecta a la libertad de actuación en el mercado y debe ser respetuosa con el contenido esencial de la libertad de empresa.

3. La impartición de las órdenes necesarias para asegurar el abastecimiento de los mercados en situaciones de desabastecimiento de productos de primera necesidad [art. 11.e)]. Una medida tal, en cuanto afecte negativamente a la libertad del empresario de actuar en el mercado o a su libertad de organización, debe ser respetuosa con el contenido esencial de la libertad de empresa, a menos que implique una intervención de empresas, en cuyo caso deberá justificarse en el artículo 12.2 LOAES.

Amén de estas medidas expresas y específicas, el artículo 12.1 LOAES habilita a la autoridad competente en el estado de alarma para adoptar las medidas establecidas en las normas para la lucha contra las enfermedades infecciosas, cuando se declare el estado de alarma en razón del supuesto b) del artículo 4 LOAES (crisis sanitarias, tales como epidemias ...). Por esta puerta se da entrada a la legislación sanitaria para hacer frente a crisis de este tipo (el llamado Derecho ordinario de necesidad), tanto estatal como autonómica. La legislación estatal al respecto se contiene en tres leyes: la LO 3/1986, de 14 de abril, de Medidas Especiales en Materia de Salud Pública (LOMESP), en particular su artículo 3; la Ley 14/1986, de 25 de abril, General de Sanidad (LGS), en particular, su artículo 26; y la Ley 33/2011, de 4 de octubre, General de la Salud Pública (LGSP), en particular su artículo 54. Estas tres leyes estatales facultan a las autoridades sanitarias (estatales o autonómicas) a adoptar una amplia variedad de medidas concretas para hacer frente a crisis sanitarias y, como cierre, a modo de cláusula general, las que estimen necesarias a tal fin. Entre las medidas concretas están dos que impactan directamente sobre la libertad de empresa: la suspensión del ejercicio de naturaleza [art. 11.c)]. 
actividades o el cierre temporal de empresas e instalaciones (art. 26 LGS y 54 LGS) ${ }^{19}$.

\section{LA LIBERTAD DE EMPRESA DURANTE LA VIGENCIA DEL ESTADO DE ALARMA DECLARADO EL 14 DE MARZO DE 2020}

1. La declaración del estado de alarma y la libertad de empresa

\section{a) Consideraciones generales}

El estado de alarma se declaró el 14 de marzo de 2020 mediante Real Decreto $463 / 2020$ y se prolongó, mediante sucesivas prórrogas (seis) hasta el 21 de junio de 2020. Cierto es que las medidas previstas en el mismo se fueron relajando desde la aprobación por el Consejo de Ministros del llamado Plan de Transición Hacia la Nueva Normalidad (el 28 de abril de 2020). De todas estas medidas interesan, obviamente, las que tuvieron un impacto directo (potencial o real) en la libertad de empresa. Las clasifico de la siguiente forma:

a) En primer lugar, medidas no directamente aplicables, sino que habilitan a las autoridades competentes delegadas a actuar específicamente. Son habilitaciones específicas respecto de la genérica del artículo $4.3^{20}$ :

a).1. Unas son de carácter facultativo: las que facultan a las autoridades delegadas competentes, 1) bien a impartir las órdenes precisas para asegurar el abastecimiento del mercado y el funcionamiento de los servicios de los centros de producción afectados por el desabastecimiento de productos necesarios para la protección de la salud pública [art. 13.a)] o el suministro de energía eléctrica [art. 17]; 2) bien a intervenir locales [incluidos los establecimientos sanitarios de titularidad privada -art. 13.b)]

19 Durante la vigencia de estado de excepción, la LOAES faculta también para adoptar esta medida (art. 26).

20 En el artículo 4.3 del decreto de declaración del estado de alarma se habilita a los 4 ministros designados como autoridades competentes delegadas (Defensa, Interior, Transportes y Sanidad) a dictar las órdenes, resoluciones, disposiciones e instrucciones interpretativas necesarias para garantizar la prestación de todos los servicios, ordinarios o extraordinarios, en orden a la protección de personas, bienes y lugares, sin que sea precisa tramitación de procedimiento alguno. 
o a intervenir empresas para garantizar el abastecimiento alimentario (art. 15.2). Su base jurídica está en los artículos 11 y 12.2 LOAES $^{21}$.

El impacto de estas habilitaciones sobre la libertad de empresa dependía de su ejercicio por la autoridad competente. Hasta donde yo sé, no se hizo uso de la habilitación para intervenir locales o empresas. Sí se hizo uso de la primera, por ejemplo, para garantizar el abastecimiento y fabricación de determinados medicamentos, en la Orden SND/276/2020, de 23 de marzo. En ella se obliga a los fabricantes y distribuidores comerciales de determinados medicamentos a establecer las medidas necesarias que permitan garantizar su abastecimiento (apartado cuarto) y, además, se faculta al Ministro de Sanidad a ordenar que se priorice su fabricación (quinto). Se trata de medidas que afectan al ejercicio de la libertad de empresa de los empresarios concernidos pero que superan el test del TC para las limitaciones al ejercicio de la libertad de empresa ${ }^{22}$ : son medidas razonables (idóneas para alcanzar el fin inmediato -garantizar el abastecimiento- y mediato -proteger la vida y la salud de la población-) y no la impiden en la práctica.

a).2. Otras se presentan como obligatorias: las que mandan a las autoridades competentes a garantizar el abastecimiento alimentario interno (art. 15.1) o el que viene de fuera (art. 16), facilitando la tarea de los transportistas ${ }^{23}$. Su base jurídica es el art. 11.e) LOAES.

Su impacto sobre la libertad de empresa, a priori, es positivo. Afortunadamente -y hasta donde yo sé-, durante la vigencia del estado de alarma no se produjeron situaciones de desabastecimiento alimentario.

b) En segundo lugar, están las medidas directamente aplicables y de alcance general: por un lado, las medidas que más crudamente ha impactado sobre la actividad económica y sobre la libertad de empresa, las del artículo 10, a la que

21 El artículo 13.c) habilita también al Ministro de Sanidad a practicar requisas temporales de bienes. El decreto es reiterativo. Ya antes, en el artículo 8.1, habilita a las autoridades competentes delegadas a acordar que se practiquen requisas temporales de todo tipo de bienes necesarios para el cumplimiento de los fines del decreto. Aquí está afectado principalmente el derecho de propiedad [Sobre esta cuestión, Álvarez García y otros, 2020: $\mathrm{XXI}$. No me consta que durante el estado de alarma se practicara requisa temporal de bien alguno.

22 Vid supra, II.

23 El protagonismo recayó en el Ministro de Transportes: una relación de las Órdenes dictadas por este durante la vigencia del estado de alarma se puede encontrar en el Código COVID-19 del BOE, accesible por internet. 
dedicaré atención especial; por otro lado, las medidas en materia de transportes del artículo 14.

En el artículo 14 encontramos habilitaciones específicas al Ministro de Transportes, facultativas (apartado 1$)^{24}$ y obligatorias (apartado 4$)^{25}$. También encontramos (en el apartado 2) medidas directamente aplicables y de alcance general, que tienen por destinatarios a dos grupos de empresarios distintos: los que prestan el servicio de transporte público de viajeros (por carretera, ferroviario, aéreo y marítimo) con sujeción a un contrato público o a una obligación de servicio público [letra b)] y los que lo prestan sin esa sujeción [letra a)]. La actividad de los primeros es una actividad "publificada" (total o parcialmente) por lo que está sustraída (total o parcialmente) a la libertad de empresa. La actividad de los segundos se desarrolla en régimen de libre empresa y, por consiguiente, el legislador debe ser respetuoso con su contenido esencial. Me interesan, por tanto, los empresarios de la letra a). Pues bien, el decreto de declaración del estado de alarma (que -como es sabidotiene rango de ley), les obliga a reducir su oferta total de operaciones al menos un $50 \%{ }^{26}$.

Una reducción de tal cuantía es una injerencia intensa en el ejercicio de la libertad de empresa, en particular, en la libertad de contratación. ¿Supera el test de constitucionalidad del TC para las limitaciones al ejercicio de la libertad de empresa? Parece que sí: la medida es, una vez, más razonable, en el sentido de idónea para alcanzar el fin propuesto (el inmediato, limitar la libertad de circulación; el mediato, proteger la vida y la salud de la población) y no impide en la práctica el ejercicio de la actividad empresarial, aunque la dificulta notablemente. A este respecto: ¿Podían permitirse las empresas de transporte una reducción a la mitad de su cifra de negocios, aunque fuera temporalmente? No lo sé.

24 Se le faculta para dictar los actos y disposiciones necesarias para establecer condiciones a los servicios de movilidad.

25 Apartado introducido por el Real Decreto 465/2020, de 17 de marzo, por el que se modificó el decreto de declaración del estado de alarma. En él se manda al Ministro de Transportes a que, mediante resolución, establezca las condiciones necesarias para facilitar el transporte de mercancías en todo el territorio nacional, con objeto de garantizar el abastecimiento y la entrega de productos adquiridos en el comercio por internet, telefónico o por correspondencia. Véase a este respecto la Orden TMA/254/2020, de 18 de marzo, por la que se dictan instrucciones en materia de transporte por carretera y aéreo.

26 Además, se habilita al Ministro de Transportes a modificar dicho porcentaje y a establecer condiciones específicas al respecto, mediante resolución. Salvo descuido por mi parte, no he visto publicado en el BOE ninguna resolución del Ministro en la que se modificara el porcentaje. 
b) En particular, el artículo 10 del decreto de declaración del estado de alarma $^{27}$

Entre las que denomina el decreto medidas de "contención", están las del artículo 10, un largo artículo que me permito desgranar así:

1. Ámbito de aplicación: es el sector de servicios de nuestra economía, en concreto, la actividad comercial, los equipamientos culturales, los establecimientos y actividades recreativas, las actividades de hostelería y restauración y otras adicionales (incluidas en el anexo del decreto).

2. Medidas adoptadas: son medidas de alcance general, dirigidas a una pluralidad indeterminada de sujetos, pero directamente aplicables (no son meras habilitaciones). Son estas:

a. La suspensión de la apertura al público de todos los locales y establecimientos minoristas, a excepción de unos cuantos que -se supone- se consideran esenciales ${ }^{28}$ (ap. 1). Aun para estos últimos, se imponen exigencias de permanencia rigurosas ${ }^{29}$.

b. La suspensión de la apertura al público, de los locales y establecimientos en los que se desarrollen espectáculos públicos, amén de los museos, archivos, bibliotecas y monumentos y de las actividades deportivas y de ocio (la relación completa, en el anexo del decreto).

c. La suspensión de las actividades de hostelería y restauración, salvo el servicio de entrega a domicilio.

27 Mediante Real Decreto 465/2020, de 20 de marzo se modificó el apartado 1 y el título del anexo y que incluyó el apartado (vid. su Artículo Único Dos); y en el Real Decreto 492/2020, de 24 abril, por el que se prorrogó por tercera vez el estado de alarma, que modificó el apartado 6 (vid. la Disposición Final Primera Dos).

28 Los establecimientos comerciales minoristas de alimentación, bebidas, productos y bienes de primera necesidad, establecimientos farmacéuticos, sanitarios, centros o clínicas veterinarias. ópticas y productos ortopédicos, productos higiénicos, prensa y papelería, combustible para automoción, estancos, equipos tecnológicos y de telecomunicaciones, alimentos para animales de compañía, comercio por internet, telefónico o correspondencia, tintorerías, lavanderías y el ejercicio profesional de la peluquería. Se añadía una cláusula habilitadora a la autoridad competente para suspender la actividad de cualquier establecimiento que puede suponer un riesgo de contagio por las condiciones en la que se esté desarrollando.

29 "La permanencia en los establecimientos comerciales cuya apertura esté permitida deberá ser la estrictamente necesaria para que los consumidores puedan realizar la adquisición de alimentos y productos de primera necesidad, quedando suspendida la posibilidad de consumo de productos en los propios establecimientos" (ap.2, párrafo primero). "En todo caso, se evitarán aglomeraciones y se controlará que consumidores y empleados mantengan la distancia de seguridad de al menos un metro a fin de evitar posibles contagios" (ap. 2, párrafo segundo). 
d. La suspensión de las verbenas, desfiles y fiestas populares (con la consiguiente afectación al sector de los feriantes).

3. Habilitación específica: se habilita al Ministro de Sanidad para modificar, ampliar o restringir las medidas, lugares, establecimientos y actividades enumeradas, por razones justificadas de salud pública, con el alcance y el ámbito territorial que específicamente se determine (apartado 6). Al amparo de esta norma, el Ministro de Sanidad ordenó la suspensión de la apertura al público de los establecimientos de alojamiento turístico (Orden SND/257/2020, de 19 de marzo). También al amparo de esta norma, aunque junto con la genérica del artículo 4.3, determinó la relación de centros, servicios y establecimientos sanitarios que se consideran esenciales a los efectos de lo previsto en el Real DecretoLey 9/2020, de 20 de marzo (Orden SND/310/2020, de 31 de marzo).

Como se ve, en el artículo 10 se decretó directamente el cierre de establecimientos o la suspensión de actividades, esto es, la paralización casi total de la actividad de una buena parte del sector terciario o de servicios, que, no olvidemos, supone casi el $70 \%$ del PIB del país ${ }^{30}$. La paralización, que se extendió a toda actividad económica no esencial durante 10 días, tras la aprobación del Real Decreto-Ley 10/2020 (del que me ocupo después), se fue relajando progresivamente con la puesta en práctica del Plan de Transición a la Nueva Normalidad por el Consejo de Ministros (Acuerdo del Consejo de Ministros de 28 de abril de 2020) ${ }^{31}$. El plan preveía un proceso de desescalada asimétrico (por provincias, islas $u$ otras unidades territoriales), coordinado con las comunidades autónomas ${ }^{32}$ y progresivo, por fases (de la 0 a la 3$)^{33}$, hasta la finalización del estado de alarma. La decisión del paso a las distintas fases

30 En 2018, el 67,71\% (fuente: https://es.statista.com/estadisticas/501643/distribucion-delproducto-interior-bruto-pib-de-espana-por-sectores-economicos/).

31 Nunca publicado, aunque sí comunicado al Congreso, en aplicación de la Disposición Adicional Sexta del decreto de declaración de estado de alarma (introducida por el Real Decreto 476/2020, por el que se aprobó la primera prórroga del estado de alarma).

32 Es la famosa "cogobernanza", articulada jurídicamente mediante una Orden SND/387/2020, de 3 de mayo.

33 Por razones de espacio, no puedo detenerme en este asunto. Pondré como ejemplo la hostelería y la restauración: en fase 0 se permitirían pequeños resquicios (además del servicio a domicilio, la recogida del producto por el cliente en el establecimiento); en fase 1 se permitiría la reapertura de las terrazas con limitaciones (no más del $50 \%$ de la mesas habituales y no más de 10 personas en cada una ellas); en fase 2 se permitiría también la reapertura al público para consumo en el interior del local, con una reducción de aforo del $50 \%$ (entre otros requisitos); y en fase 3 se permitiría el consumo en barra (con condiciones) y se ampliaría el aforo de las terrazas al $70 \%$. 
recayó en el Ministro de Sanidad, hasta la aprobación de la sexta prórroga, en que recayó en las propias comunidades autónomas ${ }^{34}$.

En definitiva, lo que se produjo a partir del 14 de marzo de 2020 y, como mínimo, hasta la puesta en práctica (progresiva y asimétrica) del plan de desescalada, fue "una disrupción temporal y generalizada de la actividad económica", "especialmente acusada en el sector terciario, y muy particular en el turismo y la hostelería, dos de los motores económicos del país". No son palabras mías, sino del propio Gobierno ${ }^{35}$. Este se cuidó mucho de precisar el distinto carácter de las medidas para la movilidad de la población y las de contención de la actividad económica adoptadas en el decreto de declaración de estado de alarma: restricción en un caso, paralización o suspensión en otro $^{36}$. No tuvo pudor, por tanto, en declarar que se produjo una suspensión de la actividad económica, especialmente en el sector terciario.

Las consecuencias económicas de las medidas de contención fueron conocidas: en el segundo trimestre de 2020 el PIB español se desplomó en un $18,5 \%$, la caída más alta de toda la Unión Europea. Pero este jurista debe preguntarse no por las consecuencias económicas, sino por las consecuencias jurídicas de las medidas de "contención" de la norma del artículo 10 del decreto de estado de alarma. Recuerdo que es una norma con rango de ley que, como tal, debe respetar el contenido esencial de los derechos fundamentales. ¿Respeta el contenido esencial de la libertad de empresa una prohibición temporal, sí, pero (casi) general y (casi) absoluta de la actividad económica en sectores tan relevantes como el comercio minorista, la hostelería y restauración o los hoteles y alojamientos turísticos?

34 Conforme al artículo 6 del Real Decreto 555/2020,de 5 de junio (última prórroga del estado de alarma), los Presidentes de las comunidades autónomas asumieron en exclusiva la adopción, supresión, modulación y ejecución de medidas en la fase 3, salvo para las medidas vinculadas a la libertad de circulación que excedieran del ámbito territorial de la unidad territorial determinada para cada comunidad autónoma; y las comunidades autónomas serían las que podrían decidir la superación de la fase $3 \mathrm{y}$, por tanto, la entrada a la "nueva normalidad".

35 El primer entrecomillado lo encontrará el lector en el preámbulo del Real Decreto-Ley $8 / 2020$, de 17 de marzo; el segundo, en el 13/2020, de 31 de marzo. Las alusiones a que durante la alarma se produjo una paralización o suspensión de numerosas actividades económicas es constante en los preámbulos de los decretos-leyes aprobados durante la vigencia del estado de alarma.

36 Véase, por ejemplo, el preámbulo del Real Decreto-Ley 17/2020, de 5 de mayo o el del Real Decreto-ley 21/2020, de 9 de junio. En este último se dice textualmente que las medidas de contención han supuesto "reducir la actividad económica y social de forma temporal, restringiendo la movilidad y paralizando la actividad en numerosos ámbitos". 
Si el parámetro de control es el tradicionalmente empleado por el TC, no hay ningún problema de constitucionalidad. La medida afectó (¡y de qué manera!) a la libertad de ejercicio de la actividad empresarial de buena parte de los empresarios del sector servicios. Pero la medida era a priori (y lo fue a posteriori) idónea para alcanzar el fin previsto: el inmediato, restringir la movilidad, y el mediato, proteger la vida y la salud de las personas (arts. 15 y $43 \mathrm{CE}$ ). Pero si el respeto al contenido esencial de la libertad de empresa se queda en esto, nuestra sufrida libertad no vale gran cosa como derecho fundamental. Es más, no debería calificarse como derecho fundamental, sino como mero principio rector, dejado a merced del legislador, sin más control que el de interdicción de la arbitrariedad de los poderes públicos (que es en lo que consiste en realidad el test de idoneidad o razonabilidad).

Ahora bien, si el parámetro de control es el que se aprecia en la jurisprudencia más reciente del TC (SSTC 89 y 111/2017) ${ }^{37}$, las cosas pueden cambiar. Si nos la creemos (y, sobre todo, si se la cree el propio TC), es factible concluir que una prohibición general y casi absoluta (con excepciones que confirman la regla) de ejercer la actividad empresarial en determinados sectores de actividad económica, constituye una limitación de tal intensidad de la libertad de empresa que determina un impedimento práctico de su ejercicio. Porque esto es precisamente lo que pasó: que se impidió el ejercicio de la libertad de empresa a los empresarios incluidos dentro del ámbito de aplicación del artículo 10 del decreto de declaración del estado de alarma, que no fueron precisamente pocos. Por muy buenas razones, pero se impidió.

Se puede argüir que las medidas adoptadas en el artículo 10, amén de imprescindibles e inevitables para afrontar el drama que se vivió allá por marzo, fueron temporales, por lo que no implicaron un impedimento definitivo y, por tanto, absoluto, del ejercicio de la actividad empresarial ${ }^{38}$. Pero razonar así significa diluir toda diferencia entre suspensión y no suspensión de los derechos fundamentales, a efectos del artículo 55.1 CE. Si una prohibición general del ejercicio de un derecho fundamental (pongamos por caso, el

37 Vid. supra, II.

38 Este argumento parece deslizarlo el Gobierno en el preámbulo del Real Decreto 492/2020, de 24 de abril (tercera prórroga del estado de alarma): “... el carácter limitado en el tiempo de las medidas de contención para hacer frente a la gestión de la crisis sanitaria, junto con las medidas que de forma simultánea se están articulando en materia socioeconómica, permitirán paliar el impacto de las primeras sobre el conjunto del tejido productivo ..." 
derecho de reunión) no lesiona su contenido esencial por el hecho de ser temporal, ¿qué es entonces una suspensión de un derecho fundamental? ${ }^{39}$.

Pero, claro está -se podrá argüir también- la libertad de empresa no es un derecho fundamental como los demás (por lo menos, como los de la sección 1. a del capítulo II del título I CE), sino un derecho fundamental ma non troppo, debilitado, cuyo ejercicio puede ser prohibido con carácter general en situaciones de necesidad, siempre que se haga de forma temporal y con respeto al principio de proporcionalidad. Al fin y al cabo, las leyes estatales sanitarias vigentes (a la que puede apelar la declaración de alarma ex artículo 12.2 LOAES) facultan a las autoridades sanitarias a suspender el ejercicio de actividades $\mathrm{o}$ a cerrar temporalmente empresas y sus instalaciones en crisis sanitarias como la que hemos vivido y todavía seguimos viviendo ${ }^{40}$. Pero si al amparo de estas leyes se puede suspender con carácter general el ejercicio de la libertad de empresa sin que ello implique lesión su contenido esencial ¿se puede seguir sosteniendo -como sostiene el TC- que es un derecho fundamental? Creo que no.

39 Para mí, una suspensión de un derecho fundamental ex artículo 55.1 CE no es necesariamente una cesación temporal total de su vigencia o de su eficacia, puede ser parcial. Así lo atestigua la regulación de la LOAES de las suspensiones de derechos fundamentales en el estado de alarma. La línea que separa una limitación (temporal) del ejercicio de un derecho fundamental y una suspensión de este es precisamente la regla de respeto a su contenido esencial (art. 53.1 CE). En el estado de alarma se puede limitar (temporalmente) el ejercicio de derechos fundamentales, pero no lesionar su contenido esencial. En los estados de excepción y sitio se puede "lesionar" el contenido esencial de algunos de ellos (los del artículo 55.1 CE), como excepción, prevista en la CE, a la regla del artículo 53.1 CE. El contenido esencial es resistente al legislador, no a la CE misma, como vengo sosteniendo, precisamente en relación con la libertad de empresa. Es excepción específica para esta el artículo 128.2 CE. Sobre esta cuestión, Cidoncha Martín, 2020: 129.

40 Arts. 26 LGS y 54 LGSP (ya citados). La propia LOAES parece conspirar a favor de este argumento. Una de las medidas que faculta a adoptar a la autoridad gubernativa cuando se declara el estado de excepción es la suspensión temporal de actividades de las industrias 0 comercios que puedan motivar la alteración del orden público, así como a ordenar el cierre provisional de salas de espectáculos, establecimientos de bebidas y locales de similares características (art. 26). Entiendo que el legislador orgánico era consciente de que la libertad de empresa no era un derecho fundamental suspendible.

Alguien podría pensar que la suspensión de actividades solo puede decretarse en el estado de excepción (o de sitio) porque solo se prevé expresamente para este. Sin embargo, conviene no olvidar que también se puede decretar en el estado de alarma, en virtud de la remisión que el artículo 12.2 LOAES hace a la legislación sanitaria. 
2. Los decretos-leyes aprobados durante la vigencia del estado de alarma y la libertad de empresa

\section{a) Consideraciones generales}

Entre el 14 de marzo y el 21 de junio de 2020, fecha en que se puso fin al estado de alarma, el Gobierno aprobó quince decretos-leyes ${ }^{41}$, todos ellos convalidados por el Congreso. En los días inmediatamente anteriores a la declaración de estado de alarma había empezado a moverse y había aprobado dos decretos leyes directamente relacionados con la epidemia ${ }^{42}$. Una vez finalizado el estado de alarma ( $y$ hasta el cierre de este trabajo), el Gobierno aprobó otros 8 más, uno de los cuales (el 27/2020) no fue convalidado.

Quince decretos-leyes, por tanto, fueron dictados durante la vigencia del estado de alarma, pero no al amparo o bajo la cobertura jurídica del estado de alarma. No son parte del Derecho (constitucional y legal) de alarma y, por tanto, no les alcanzan los efectos temporales que este produce sobre el ordenamiento ${ }^{43}$. Muy al contrario, el Derecho producido válidamente bajo la cobertura del estado de alarma (decretos, órdenes ...) puede desplazar (temporalmente) la legalidad ordinaria. Esto es: el Gobierno podían dictar decretos-leyes durante la vigencia del estado de alarma ${ }^{44}$, pero los quince decretos-leyes aprobados no podían invadir el espacio reservado a las normas del Derecho de alarma dictadas bajo su cobertura jurídica, ni consecuentemente, desplazarlas.

Durante, pero también antes y después de la vigencia del estado de alarma, el Gobierno solo puede dictar válidamente decretos-leyes que afecten a los derechos fundamentales si respetan los límites del artículo 86 CE y no vulneran su contenido esencial. Ocurre que el TC ha hecho una interpretación muy laxa de lo que se puede afectar o, si se prefiere, una interpretación muy restrictiva de lo que se prohíbe afectar. Para el Tribunal, el artículo 86.1 CE no prohíbe la

41 Los que van del 8/2020 al 22/2020.

42 Los Reales Decretos-leyes 6/2020, de 10 de marzo (aprobado un día antes de que la OMS declarase la crisis como pandemia) y 7/2020, de 12 de marzo (un día después).

43 Las normas (decretos, ordenes ...) aprobadas bajo la cobertura jurídica del estado de alarma forman parte de una legalidad excepcional que permite alterar el funcionamiento ordinario del sistema de fuentes, esto es, desplazar temporalmente la legalidad ordinaria; y alterar el funcionamiento ordinario del reparto competencial entre el Estado y las Comunidades Autónomas, esto es, desplazar o someter a una autoridad central el ejercicio de competencias de estas últimas durante un tiempo. Sobre los elementos esenciales del Derecho de necesidad, Álvarez García y otros, 2020: II.

$44 \mathrm{La}$ declaración del estado de alarma no interrumpe el normal funcionamiento de las instituciones del Estado (art. 1.4 LOAES). 
afectación singular del derecho, solo la afectación general ${ }^{45}$. $\mathrm{Y}$ define la afectación general (prohibida), bien como la regulación "de un régimen general" del derecho, bien como la regulación "que vaya en contra del contenido o elementos esenciales" del derecho ${ }^{46}$. Todo lo que no sea esto le está permitido al decreto-ley.

¿Qué significa ir en contra del contenido o elementos esenciales del derecho? ¿Significa que está prohibido al decreto-ley vulnerar el contenido esencial de los derechos fundamentales -todo él o de alguno de sus elementos esenciales-? Si es así, la afirmación es redundante, porque el decreto-ley, como cualquier norma con rango de ley, no puede ir en contra de ese contenido esencial, por exigencia del artículo 53.1 $\mathrm{CE}^{47}$. Pero es lo que parece decirnos el $\mathrm{TC}^{48}$. Ello reduce, en puridad, el ámbito de la expresión "prohibido afectar" un derecho fundamental del artículo 86.1 CE a "prohibido establecer el régimen general del mismo", sea lo que sea esto. La prohibición al decreto-ley de vulnerar el contenido esencial de los derechos fundamentales no tiene como base el artículo 86.1, sino el 53.1 CE.

\section{b) Consideraciones particulares desde la libertad de empresa}

No puedo entrar en el análisis jurídico-constitucional de cada uno de los quince decretos-leyes aprobados durante la vigencia del estado de alarma desde la perspectiva de la libertad de empresa. Como ya he dicho, fueron aprobados, no para hacer frente directamente a la pandemia, sino a las consecuencias económicas y sociales de las medidas de "limitación" de la libertad de circulación (el confinamiento) y de "contención" (la suspensión de actividades económicas) adoptadas por el decreto de declaración del estado de alarma. Buena parte de sus contenidos lo conforman medidas dirigidas a mitigar el impacto de las medidas de contención sobre el tejido productivo. En este sentido, son medidas que no dañan, sino que afectan positivamente a los titulares de la libertad de empresa ${ }^{49}$.

45 Una certera crítica en Aragón Reyes, 2016: 91 y 190.

46 ATC 179/2011, de 13 de diciembre (FJ 7), que recoge la doctrina del TC en este punto, según se dice en la STC 139/2016, FJ 6.

47 Aragón Reyes, 2016: 93.

48 Es la conclusión a la que llego tras la lectura de las letras a) y c) del FJ 7 del citado ATC 179/2011.

49 En puridad, las medidas han consistido, como regla general, no en ayudas directas y a fondo perdido, sino en facilidades (avales) para solicitar préstamos (que hay que devolver); no en condonaciones o deducciones fiscales, sino en el aplazamiento del pago de impuestos y 
No obstante, algunas de las medidas adoptadas han afectado negativamente a la libertad de empresa. No voy a desgranar todas ellas, tan solo las que, a mi juicio, me plantean más dudas sobre su constitucionalidad. Es el caso de la medida adoptada en el Real Decreto-ley 9/2020, de 27 de marzo. Su artículo 1 declara "servicios esenciales" los centros, servicios y establecimientos sanitarios que determine el Ministerio de Sanidad, así como los centros sociales de mayores, personas dependientes o personas con discapacidad, en los términos especificados por el Ministerio de Derechos Sociales ${ }^{50}$, cualquiera que sea la titularidad, pública o privada o el régimen de gestión (ap. 1). La consecuencia de esta declaración: la obligación de mantener su actividad durante la vigencia del estado de alarma (ap. 2), con la consiguiente prohibición de tramitar ERTEs (art. 2). Esta obligación y esta prohibición afectan, por tanto, a los centros de titularidad privada.

Esa medida afecta con carácter general a un elemento esencial de la libertad de empresa de los titulares de los centros sanitarios y de servicios sociales privados: la libertad de cesar en la actividad empresarial. La libertad de empresa comprende el derecho a iniciar y a ejercer (a sostener en libertad) una actividad empresarial, pero también el derecho a cesar en la actividad empresarial y, por tanto, a no ser obligado a ejercer una actividad empresarial si no se quiere ${ }^{51}$.

Es fácil que el Real Decreto-ley 9/2020 supere el bajo listón que el TC pone a la prohibición de afectar los derechos fundamentales ex artículo 86.1 CE. Más dudas tengo acerca de si respeta la prohibición de vulnerar su contenido esencial ex artículo 53.1 CE. Sí tengo claro que el Gobierno tenía una alternativa respetuosa con la CE y que estaba facultado a adoptar en el marco jurídico del estado de alarma: la intervención de los centros [art. 128.2 CE y arts. 11.c) LOAES y 13.b) del decreto de declaración del estado de alarma].

También me resulta problemático el Real Decreto-Ley 10/2020, de 29 marzo, el que se ha dado en llamar decreto-ley de "hibernación" de la economía. En él se regula un permiso retribuido recuperable pero obligatorio, entre el 30 de marzo y el 9 de abril de 2020, para todos los trabajadores que presten servicios en

deudas tributarias (que hay que pagar). Quizá la medida más conocida y, probablemente, la más eficaz, ha sido la flexibilización de los ERTES, para dar cabida en ellos, como causa de fuerza mayor, a la pérdida de actividad como consecuencia de la covid-19.

50 Vid. Orden SND/310/2020, de 31 de marzo, en lo que hace a los centros, servicios y establecimientos sanitarios.

51 Sobre esta cuestión, Cidoncha, 2006: 331. 
empresas o entidades del sector público o privado que desarrollan "actividades no esenciales" (calificadas como tales en un anexo). La consecuencia es la suspensión de todas esas actividades calificadas como no esenciales. Solo se permite desarrollar "la actividad mínima indispensable", esto es, "la mantenida en un fin de semana ordinario o en festivos" (art. 4).

El fin inmediato de la medida era evidente: reducir al mínimo la movilidad de la población, en el momento en el que el dichoso coronavirus golpeaba con más fuerza. El fin mediato, también: proteger la vida y la salud de las personas. Pero el fin no justificaba el medio empleado, por dos motivos. El primero, porque supuso una ampliación de las medidas de "contención" de la actividad económica establecida en el decreto de declaración del estado de alarma, que solo mediante una modificación de ese decreto se podía llevar a cabo ${ }^{52}$ : el decreto-ley no puede invadir el espacio acotado válidamente al Derecho de alarma. El segundo, porque el cierre de toda la actividad económica (salvo la esencial), impidió en la práctica y masivamente el ejercicio de la actividad empresarial en nuestro país, aunque solo fuese durante 10 días. No parece que el decreto-ley "regule el régimen general" de la libertad de empresa, pero sí parece que "vaya en contra" de un de los "elementos esenciales" de la libertad de empresa, yo diría que el elemento esencial: la libertad de ejercicio o, en palabras del TC, el derecho a sostener en libertad la actividad de empresa. Diría que va frontalmente en contra y que, por ello, vulnera el contenido esencial de la libertad de empresa ${ }^{53}$.

\section{LIBERTAD DE EMPRESA Y "NUEVA NORMALIDAD”}

El 21 de junio de 2020 finalizó el estado de alarma, pero no, desgraciadamente, la crisis sanitaria provocada por la pandemia. Durante el estado de alarma, pero pensando en el día después de su fin, el Gobierno aprobó el Real Decreto-ley 21/2020, de 9 junio, de medidas urgentes y de coordinación para

52 En el mismo sentido, Álvarez García, 2020: XVIII, aunque este autor pone el acento en que lo que se produjo fue una ampliación de las restricciones a la libertad de circulación establecidas en el decreto de alarma.

53 Doy por reproducidos aquí los razonamientos empleados en relación con el artículo 10 del decreto de declaración de estado de alarma (vid. supra IV.1.2). Es cierto que la suspensión de actividades fue más corta (solo 10 días) pero, a cambio, afectó a toda la actividad económica (salvo la esencial). 
hacer frente a la crisis sanitaria ocasionada por la covid-19. Es el llamado decreto-ley de "nueva normalidad".

En el decreto-ley se regulan una serie de medidas preventivas de diverso signo ante la eventualidad de "nuevos brotes epidemiológicos y nuevas cadenas de transmisión no identificadas" que comprometan "la garantía de la integridad física y la salud de las personas" y que sitúen "de nuevo bajo una enorme presión asistencial los recursos sanitarios disponibles" (son palabras de su exposición de motivos). Algunas de ellas contienen mandatos u obligaciones directas ${ }^{54}$, pero la mayor parte son meras directrices dirigidas a las autoridades competentes, de hecho, las autonómicas, para que se aseguren de que los titulares de actividades de contacto directo con el público (las que fueron suspendidas durante la vigencia del estado de alarma) adopten las medidas pertinentes al objeto de evitar contagios ${ }^{55}$. A tal efecto, las comunidades autónomas se aprestaron a aprobar las correspondientes medidas, que adoptaron la forma de Órdenes de las Consejerías de Sanidad ${ }^{56}$. Esto fue lo que hizo, por ejemplo, la Comunidad de Madrid, mediante Orden de su Consejería de Sanidad (Orden 668/2020, de 19 de junio) ${ }^{57}$.

La responsabilidad del control de la pandemia se hizo recaer en las comunidades autónomas, pero no hay que olvidar de que el Estado tiene competencia normativa básica y de coordinación general de la sanidad (art. 149.1.16 CE). En este sentido, debe repararse en que el art. 65 de la Ley 16/2003, de 28 de mayo, de cohesión y calidad del Sistema Nacional de Salud (modificado precisamente por el Real Decreto-Ley 21/2020) ${ }^{58}$ dispone que, "para responder a situaciones de especial riesgo o alarma para la salud pública", el Ministerio de Sanidad podrá adoptar una "declaración de actuaciones coordinadas en salud pública", previo acuerdo del Consejo

54 V.gr., arts. 7 y 19.

55 Vr.gr., arts. 11 a 16.

56 Estas disposiciones, aprobadas en junio, poco después de la aprobación del decreto-Ley de nueva normalidad, las puede encontrar el lector en el CODIGO COVID-19 del BOE, permanentemente actualizado y accesible por internet.

57 Madrid fue la comunidad más golpeada por el coronavirus y, además, pasó a la "nueva normalidad" sin ni siquiera haber pasado a la fase 3 de la desescalada, al decaer el estado de alarma. De ahí que en esa Orden se previera una desescalada progresiva del comercio minorista y de la hostelería y restauración y que incluso se prohibiera la apertura de los locales de ocio nocturno hasta el 6 de julio de 2020.

58 Disposición Final Segunda del Real Decreto-Ley 21/2020, que modifica el art. 65 de la Ley 16/2003 e introduce un nuevo art. 65 bis (Aportación de información al Ministerio de Sanidad en situaciones de emergencia para la salud pública). 
Interterritorial del Sistema Nacional de Salud (CISNS), en el que están representadas todas las comunidades autónomas ${ }^{59}$.

El incremento sustancial de brotes epidémicos llevó a que el CISNS se reuniera el 14 de agosto de $2020^{60}$. Ese mismo día se acordaron por unanimidad una serie de medidas, entre ellas, para lo que aquí nos interesa, el cierre general de los locales de ocio nocturno, en los que se habían detectado brotes de la epidemia. El acuerdo se tradujo jurídicamente en una declaración de actuaciones coordinadas de ese mismo día, nunca publicada en el $\mathrm{BOE}^{61}$. Las comunidades autónomas debían implementar las medidas previstas en esa declaración, entre ellas, el citado cierre general de los locales de ocio nocturno. Esto fue lo que hizo, por ejemplo, la Comunidad de Madrid, mediante Orden de su Consejería de Sanidad (Orden 1008/2020, de 18 de agosto), dictada precisamente en aplicación de la citada declaración de actuaciones coordinadas. En su apartado seis se decreta la suspensión de actividades de los locales de discoteca y demás establecimientos de ocio nocturno hasta la finalización de la vigencia de dicha declaración de actuaciones.

¿Pueden las comunidades autónomas decretar, mediante una simple orden, el cierre generalizado del ejercicio de la libertad de empresa en un sector de la economía "hasta nuevo aviso"? No, desde luego, al amparo de una no publicada "declaración de actuaciones coordinadas", que no vincula a los ciudadanos. La base tampoco puede ser el precepto que las prevé, el artículo 65 de la Ley 16/2003, pues no respeta en absoluto las exigencias de la reserva de ley en materia de derechos fundamentales fijadas por el TC ${ }^{62}$. De existir una base legal, hay que buscarla en otra parte.

59 Salvo en situaciones de urgente necesidad, en cuyo caso el Ministerio tomará las medidas estrictamente necesarias e informará de manera urgente de las medidas adoptadas. Con esta excepción, el art. 65 de la Ley es más una manifestación de cooperación (o de cogobernanza, como se dice ahora) que de coordinación sensu stricto.

60 Ya se había reunido con anterioridad (el 16 de julio de 2020) para aprobar un "Plan de Respuesta Temprana en un escenario de control de la pandemia por Covid-19".

61 Pero comunicada, mediante Orden (Orden comunicada), a todas las Comunidades Autónomas. Algunas de ellas la publicaron en su Boletín Oficial (v.gr., Castilla y León: BOCL de 16 de agosto de 2020).

62 Por todas, STC 76/2019, de 22 de mayo (FFJJ 7 y 8), que exige que la ley especifique el interés público que permita la limitación y que establezca las restricciones posibles al derecho y las garantías adecuadas. Que este precepto no ofrece cobertura jurídica a la limitación del ejercicio de derechos fundamentales (en concreto, para confinar poblaciones enteras) lo declaró el Tribunal Superior de Justicia de la Comunidad de Madrid (Auto 128/2020, de 8 de octubre, de su Sala de lo Contencioso-administrativo, sección Octava). En consecuencia, este Tribunal denegó la ratificación de las medidas de confinamiento perimetral de Madrid y otras 9 ciudades de la Comunidad de Madrid previstas en la Orden 1273/2020, de 1 de octubre, de la 
Esa base legal podría ser la legislación sanitaria de necesidad, ya citada: la LOMESP, en particular el artículo 3; el artículo 26 de la LGS y el 54 de la LGSP. En relación con esta legislación se ha planteado un doble debate jurídico, a cuenta de los confinamientos de poblaciones adoptados por las autoridades autonómicas antes y después de la vigencia del estado de alarma. El primero: si dicha legislación, en particular, el artículo 3 LOMESP, respeta las exigencias de la reserva de ley fijadas por el TC, a que antes me he referido ${ }^{63}$. El segundo: si esta legislación habilita a las autoridades sanitarias para adoptar medidas de limitación del ejercicio de los derechos fundamentales de alcance general o solo de alcance individual ${ }^{64}$.

Ciertamente, el segundo debate lo ha querido zanjar el legislador, no por la vía directa de la modificación de la legislación sanitaria ${ }^{65}$, sino por una vía indirecta, la modificación de la Ley de la Jurisdicción ContenciosoAdministrativa (LJCA), operada por la Ley 3/2020, de 18 de septiembre, de medidas procesales y organizativas para hacer frente al covid-19 en el ámbito de la Administración de Justicia. Desde el 20 de septiembre de 2020 (fecha de entrada en vigor de la modificación), a efectos de autorización o ratificación judicial de las medidas de las autoridades sanitarias que impliquen "limitación o restricción" de derechos fundamentales, hay que distinguir según el alcance subjetivo de las mismas. La competencia para conocer de las medidas de alcance individual $^{66}$ corresponde a los juzgados de lo contenciosoadministrativo (nuevo art. 8.6 LJCA). La competencia para conocer de las que sean de alcance general ${ }^{67}$ corresponde a la Sala de lo Contencioso-

Consejería de Sanidad de la Comunidad de Madrid, dictada en ejecución de la Orden del Ministro de Sanidad de 30 de septiembre de 2020, por la que se aprueban actuaciones coordinadas en salud pública. Para cubrir jurídicamente dichas medidas, el Gobierno decretó el estado de alarma al territorio de 9 municipios de Madrid -finalmente se descolgó Alcalá de Henares-, mediante Real Decreto 900/2020, de 9 de octubre.

63 Véase, por ejemplo, Saénz Royo: 2020 vs Doménech Pascual: 2020.

64 Véase, por ejemplo, Doménech: 2020 vs Barnes: 2020.

65 La letra de las leyes sanitarias da a entender que solo habilitan a adoptar medidas de alcance individual: las medidas que se pueden adoptar "se fijarán para cada caso" (art. 26.2. LGS) y "previa audiencia de los interesados, salvo en caso de riesgo inminente y extraordinario para la salud de la población" (art. 54.3 LGSP). No parece casar "conceder audiencia previa al interesado" con dictar medidas de alcance general. Como tampoco el que el citado art. 54.3 LGSP añada que los gastos derivados de la adopción de medidas cautelares contempladas en el citado artículo "correrán a cargo de la persona o empresa responsable". El legislador está pensando en personas determinadas, no en una pluralidad indeterminada de ellas.

66 Medidas "que estén plasmadas en actos administrativos singulares que afecten individualmente a uno $o$ varios particulares concretos e identificados de manera individualizada".

67 Medidas cuyos "destinatarios no estén identificados individualmente". 
Administrativo de la Audiencia Nacional [nuevo art. 11.1.i) LJCA] o a las Salas de lo Contencioso-administrativo de los Tribunales Superiores de Justicia (nuevo art. 10.8 LJCA), según que la autoridad sanitaria que las adopte sea estatal o distinta de la estatal ${ }^{68}$.

Tras esta reforma, hay que entender que las autoridades sanitarias pueden adoptar medidas que limiten o restrinjan el ejercicio de los derechos fundamentales "con" alcance general, dirigidas a "destinatarios no identificados individualmente", pues de lo contrario, no se explicaría esa nueva competencia de la Audiencia Nacional o de los Tribunales Superiores de Justicia de las Comunidades Autónomas ${ }^{69}$.

Pero traslademos el debate al derecho fundamental que nos ocupa, la libertad de empresa, y al caso que nos ocupa. Volvamos a preguntarnos: ¿Pueden las autoridades sanitarias decretar, mediante una simple orden, el cierre temporal del ejercicio de la libertad de empresa en un sector de la economía con base en la legislación sanitaria ${ }^{70} \mathrm{Ni}$ el Ministro de Sanidad, ni las comunidades autónomas, que, por unanimidad, acordaron la declaración de actuaciones coordinadas del 10 de agosto de 2020, vieron problema alguno en que se pudiera suspender con carácter general el ejercicio de la libertad de empresa de los titulares de los locales de ocio nocturno (hasta nueva orden o, mejor, hasta nueva declaración de actuaciones coordinada). A lo que parece, tampoco vieron problema alguno los jueces ${ }^{71}$. Y, hasta donde yo sé, la doctrina, muy

68 La tramitación de todas las autorizaciones o ratificaciones (de alcance individual o general) tendrá siempre carácter preferente y deberá resolverse en un plazo máximo de tres días naturales y en ella será parte el Ministerio Fiscal (nuevo art. 122 quater).

69 Ello resulta difícilmente conciliable con la letra de las leyes sanitarias (vid. nota 65) ¿Por qué no se ha modificado la legislación sanitaria, para que sea coherente con la modificación de la legislación procesal?

70 La pregunta podría hacerse también en relación con la LOAES: el ya citado art. 26 faculta a la autoridad competente, en el estado de excepción, a suspender temporalmente las actividades de industrias y comercios y a cerrar provisionalmente salas de espectáculos, establecimientos de bebidas y locales similares; siendo así que la libertad de empresa no está dentro del elenco de derechos que puede ser suspendido con carácter general ex art. 55.1 CE. Por lo demás, el "caso que nos ocupa", la suspensión de las actividades de los locales de ocio nocturno en Madrid (apartado seis de la Orden 1008/2020), es un imperativo "general", por razón del destinatario (una pluralidad indeterminada de sujetos) pero "concreto" por razón del objeto (regula un supuesto de hecho singular e irrepetible). Es un acto administrativo general o plúrimo (sobre esta cuestión, Salamero Teixidó: 2020).

71 Una muestra, la suerte que corrió la misma Orden 1008/2020, de 18 de agosto, de la Consejería de Sanidad de la Comunidad de Madrid. Esta solicitó del Juzgado de lo Contencioso-Administrativo de Madrid la ratificación judicial de algunas de las medidas previstas en la citada Orden, por entender que podían suponer privación o limitación de algún derecho fundamental. Entre ellas no estaba la del apartado seis, la suspensión de las actividades de los locales de ocio. Ni el juzgado que denegó la ratificación judicial de la Orden 
entretenida con los confinamientos, no se ha planteado la pregunta que aquí hago.

Yo sí me hago la pregunta y trato de responderla. En verdad, si la pregunta es si las leyes sanitarias dan cobertura legal suficiente a medidas de suspensión (sin adjetivar) de actividades económicas, mi respuesta es sí: tanto el artículo 26.1 de la LGS como el artículo 54.2.c) de la LGSP facultan expresamente a la autoridad competente a acordar la suspensión del ejercicio de actividades, en caso de que exista o se sospeche razonablemente la existencia de un riesgo inminente y extraordinario para la salud (art. 26.1 LGS) o cuando así lo requieran motivos de extraordinaria gravedad o urgencia [art. 54.2.c) LGSP]. Además, la medida está sujeta a dos condicionantes, que son otras tantas garantías normativas: temporalidad (la duración de la medida no excederá de lo que exija la situación de riesgo que la justificó (arts. 26.2 LGS y 54.3 LGSP) y proporcionalidad (art. 54.3 LGSP). A las garantías normativas se debería añadir la garantía judicial: la autorización (previa) o ratificación (a posteriori) judicial de la medida (ahora, arts. 8.6, 10.8 y 11.1.j) LJCA). Creo, por tanto, que se cumplen razonablemente las exigencias del TC sobre la reserva de ley en materia de derechos fundamentales.

Ahora bien, si la pregunta es si las leyes sanitarias habilitan para decretar una suspensión del ejercicio de la libertad de empresa con "alcance general", mi respuesta es no. Es cierto que, tras la reforma de la LJCA, se puede entender que las leyes sanitarias habilitan para limitar o restringir con "alcance general" el ejercicio de derechos fundamentales, entre ellos, la libertad de empresa, siempre contando con autorización o ratificación judicial ${ }^{72}$. Sucede que,

(por razones que no vienen al caso) ni el TSJ de la Comunidad de Madrid (Sala de lo contencioso-administrativo, sección 8.a ) que enmendó al juzgado (sentencia 594/2020, de 28 de agosto) se pronunciaron al respecto.

72 Así, medidas tales como limitaciones del aforo o de los horarios de los establecimientos comerciales, que, a mi juicio, son limitaciones del ejercicio de la libertad de empresa, debieran someterse a autorización o ratificación judicial. Sin embargo, no parece que esté siendo esta la práctica de las autoridades. La práctica está siendo dar por sentado que no hay limitación de derecho fundamental alguno y ello está contando con la complicidad tanto del Ministerio Fiscal como de los Tribunales.

Repárese, por ejemplo, en que, una vez entrada en vigor la reforma de la LJCA, la Comunidad de Madrid solicitó de la Sala de lo Contencioso-Administrativo del TSJ de la Comunidad de Madrid la ratificación judicial de las duras medidas para determinadas zonas de la ciudad de Madrid y de otras ciudades de la Comunidad previstas en el apartado segundo de la Orden 1178/2020, de 18 de septiembre, en tanto suponían restricción de derechos fundamentales. Una de esas medidas -la más llamativa- era la restricción de la libertad de circulación de los residentes en esas zonas (punto 1 del citado apartado segundo). Sin embargo, también había medidas que suponen limitaciones o restricciones del ejercicio de la libertad de empresa de 
obviamente, esa habilitación lo ha de ser para limitaciones o restricciones generales de los derechos fundamentales respetuosas de su contenido esencial. Con ello volvemos a la casilla de salida: si la libertad de empresa es un derecho fundamental, si su ejercicio no puede ser impedido en la práctica con alcance general, pues ello equivale a su privación [STC 89/2017, FJ 14 a)], las autoridades sanitarias no pueden acordar con alcance general la suspensión del ejercicio de la libertad de empresa en un sector económico, sea el ocio nocturno o cualquier otro, como tampoco puede el Gobierno suspender con alcance general el ejercicio de la libertad de empresa con base en la declaración del estado de alarma ${ }^{73}$.

Sin embargo, creo que las autoridades sanitarias seguirán suspendiendo actividades económicas con alcance general, cuando lo consideren urgente y necesario para la salud pública. Creo también que los órganos jurisdiccionales, en trámite de autorización o ratificación judicial, no verán necesario autorizar o ratificar tales suspensiones, porque no verán concernido ningún derecho fundamental. En verdad, nadie parece creer que aquí está en juego un derecho fundamental llamado libertad de empresa.

\section{EPÍLOGO}

Escribo estas líneas en mi condición de jurista especializado en Derecho Constitucional. Me correspondía valorar las durísimas medidas de "contención" de la actividad económica (me atengo a las expresiones empleadas por el Gobierno) adoptadas para hacer frente al coronavirus solo desde el Derecho Constitucional, desde la libertad de empresa consagrada en el art. 38 CE. Acotado así mi juicio, debo decir que estoy entre quienes piensan que la LOAES no es un traje adecuado para afrontar una pandemia como la que hemos vivido y estamos viviendo, pero tampoco la CE. Esta no habilita para

sectores económicos (v.gr., limitaciones de aforo al 50\% a los establecimientos de hostelería y restauración, tanto dentro como fuera de espacios interiores y cierre obligatorio a las $22 \mathrm{hh}$.). Sin embargo, el órgano jurisdiccional "solo encuentra concernido el derecho fundamental a la libertad de desplazamiento y circulación de las personas (consagrado en el art. 19 CE)" (FJ Cuarto del Auto 115/2020, del TSJ de Madrid, Sala de lo Contencioso-Administrativo, Sección Octava). Por tanto, solo entró a valorar la restricción de la libertad de circulación adoptada en la Orden, pero no las medidas con incidencia en la libertad de empresa. A lo que parece, para el órgano jurisdiccional estas medidas no son limitación o restricción de ningún derecho fundamental.

73 Vid. supra, IV.1.2. 
suspender con carácter general derechos fundamentales durante el estado de alarma (el estado pensado para hacer frente a epidemias) y la libertad de empresa es uno de ellos. Ni siquiera habilita para suspender con carácter general la libertad de empresa en los estados de excepción y de sitio, no pensados, por lo demás, para hacer frente a epidemias.

A mi juicio, durante la vigencia del estado de alarma se ha suspendido con carácter general el ejercicio de la libertad de empresa en una buena parte de la economía. Me temo además que, tras el fin del estado de alarma, seguirá habiendo suspensiones o restricciones generalizadas del derecho a sostener en libertad la actividad empresarial, con la percha que ofrece la legislación sanitaria, reforzada con la reforma de la LJCA. Y si la libertad de empresa es un derecho fundamental (que lo es), eso no se debe hacer ${ }^{74}$.

No es que yo reniegue de la pertinencia o necesidad de adoptar las medidas que se han adoptado y se seguirán adoptando. De lo que reniego es de intentar justificarlas jurídicamente, de ensanchar a cualquier precio el traje de nuestro Derecho para que quepan. No asumo el riesgo de que el traje se rompa. No quiero que el Derecho se desacredite. No quiero que deje de cumplir su función de límite frente al Poder. Prefiero decir que se ha infringido el Derecho (asumiendo el riesgo de ser contradicho) y exhortar a su reforma a hacerlo comulgar con lo que -a mi parecer- son ruedas de molino. Creo que soy más útil así. Creo, en fin, que puedo permitirme ese lujo.

\section{BIBLIOGRAFÍA ${ }^{75}$}

- ÁlVAREZ GARcíA, V., y otros, Coronavirus y Derecho, Foro de Investigación CSYJ, https://forocsyj.com/, 2020.

\footnotetext{
74 Me gustaría ver más claridad en el TC en relación con la libertad de empresa. Si es un derecho fundamental, debe ser tratado como los demás. La libertad de empresa es un derecho fundamental como los demás, solo que a su manera (todos los derechos fundamentales lo son "a su manera"): a su manera, porque las razones para limitarla son mayores que en otros derechos fundamentales; como los demás, porque el método de control de constitucionalidad de sus limitaciones debe ser el mismo que el de los demás derechos fundamentales. Si es un derecho fundamental, no puede ser un derecho fundamental, pero "no demasiado".

75 Solo se incluyen los trabajos expresamente citados. Obviamente, se ha manejado mucha más bibliografía.
} 
- ARAGÓN REYES, M., Uso y abuso del decreto-ley: una propuesta de reinterpretación constitucional. Discurso leído el 6 de abril de 2016 en el acto de su recepción pública como académico de número por el Excmo. Sr. D. Manuel Aragón Reyes, Real Academia de Jurisprudencia y Legislación, Madrid, 2016.

- BARNES, J., "Estado de alarma vs. legislación sanitaria y poder ejecutivo vs. Justicia”, en Almacén del Derecho, https://almacendederecho.org/, agosto 28, 2020.

- CIDONCHA, A., La libertad de empresa, Thomson-Civitas/Instituto de Estudios Económicos, Cizur Menor (Navarra), 2006.

- "Algunas ideas a propósito del famoso artículo 7 del decreto de declaración de estado de alarma", en VV. AA: 20 reflexiones jurídicas en tiempo de confinamiento. Liber Amicorum en homenaje a Cristina Izquierdo Sans, 2020.

- DOMÉNECH PASCUAL, G., "Comunidades autónomas, derechos fundamentales y covid-19. El rebrote de la controversia", Almacén del Derecho, https://almacendederecho.org/, julio 21, 2020.

- "Responsabilidad patrimonial del Estado por la gestión de la crisis del Covid-19", El Cronista del Estado Social y Democrático de Derecho, núms. 86-87, 2020.

- NIETO GARRIDO, E., "La indemnización por daños y perjuicios causados por las medidas adoptadas durante el estado de alarma", Almacén del Derecho, https://almacendederecho.org/, septiembre 15, 2020.

- SAÉNZ ROYO, E., "Limitar derechos fundamentales durante la pandemia", Agenda Pública, El País, 14 de julio de 2020.

- SALAMERO TEIXIDÓ, L., "Algunas reflexiones sobre la autorización o ratificación judicial de medidas sanitarias al hilo de la aprobación de actos plúrimos para hacer frente a la Covid-19", Diario La Ley, núm. 9638, 2020.

- TERUEL LOZANO, G., "Los decretos-leyes en la crisis del coronavirus: perspectiva constitucional", en Tudela Aranda, J. (ed.): El Parlamento ante el Covid-19, Cuadernos Manuel Giménez Abad, Monografías 8, Fundación Manuel Giménez Abad, 2020. 
fundación

Manuel Giménez Abad

deEstudios ParlamentariosydelEstado Autonómico

- VILLAR CRESPO, G., "Repensando el Derecho de excepción: la crisis del coronavirus y los tres aprendizajes sobre el Derecho de necesidad en el ordenamiento jurídico español", Revista General de Derecho Constitucional, núm. 54, 2000. 